\title{
Forming trust with vaccine fence-sitters
}

$\mathrm{V}$ accination programs and providers should not expect to convert people from a strong antivaccination stance, according to some experts. When it comes to promoting vaccine acceptance, they argue it may be a better investment to focus on winning the trust of the "vaccine-hesitant."

There's a tendency in public health to see people as either pro- or antivaccine, but many people stand somewhere between the two camps, explains Ève Dubé, a medical anthropologist and member of the scientific group on immunization at the Quebec National Institute of Public Health. "Health care providers are seeing more and more people with questions and doubts who are not anti-vaccine. They're willing to vaccinate but they won't do it without question."

A 2012 literature review in BMC Pediatrics estimates that less than $2 \%$ of parents refuse vaccines outright, while up to $30 \%$ are hesitant to vaccinate their children. "It's a much larger group and it's a group that's much more inclined to respond to public health initiatives and be convinced," says Dubé.

On the flipside, hesitant parents are also more likely to believe negative messages about vaccines and distrust science in general. In one pan-Canadian study for the Public Health Agency of Canada, half of parents reported concerns that new vaccines are not as safe as old ones, even though 9 of 10 had fully vaccinated their children.

According to Dubé, ignoring the ambivalence at play in such decisions can polarize patients and contribute to vaccine refusals and dissatisfaction with care.

She and other experts spoke at the recent Public Health 2016 conference in Toronto about how health care workers can shore up the confidence of patients who are hesitant to vaccinate.

"Health care provider information and assurances have been shown in a number of studies to be the main reason why parents who planned to delay or refuse a

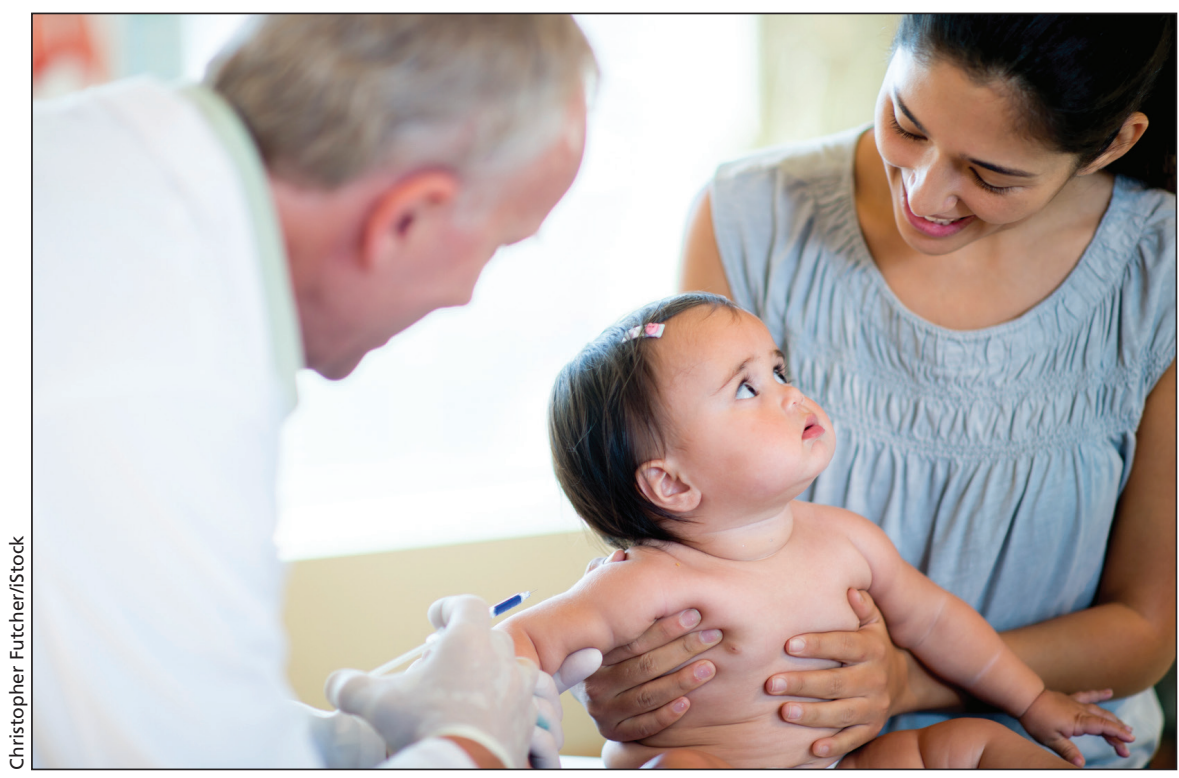

Careful listening and sharing personal stories are keys to increasing vaccine acceptance among hesitant parents, say experts.

vaccine for their child changed their minds," urged Dr. Noni MacDonald, a professor of pediatrics at Dalhousie University in Halifax. "We can really be very powerful to help patients or parents who are sitting on the fence."

The goal of interactions should be first and foremost to build trust, she added. "To have trust you have to have all the scientific information but you also have to come across as caring."

MacDonald, an advisory board member at the National Collaborating Centre for Infectious Diseases, recommended that health providers begin talking about vaccination with the assumption that patients will be vaccinated, but follow up with questions to uncover concerns. "Don't assume that you've got a problem or you may plant that problem and make it worse," she said. "Listen and listen again, make sure you understand the concerns, and then tailor your information to fit."

When addressing a patient's concerns, "keep it short, clear and at their level of language," MacDonald added. "If mom is worried about the needle and pain, she doesn't want you to talk about immunology of two-month-olds."
She urged health care providers to use their own stories of encounters with vaccine-preventable diseases to illustrate the importance of vaccination.

Ian Roe, a content strategist for the British Columbia Centre for Disease Control, noted that public health programs can also benefit from adopting a more informal approach to communicating health information. For example, the centre is combatting vaccine misinformation with a website that donates vaccines to UNICEF every time a user completes a quiz or shares an article or story about vaccination via social media.

The website, iboostimmunity.com, aims to mobilize the "silent majority" of people who are pro-vaccine but may not otherwise be willing to share that with vaccine-hesitant friends and family, explained Roe. "We're not targeting vaccine-hesitant or anti-vaccine; we're targeting the people who can influence them," he said.

The program has enough funding to donate 600000 vaccines in 2016 and 2017, Roe added. "We're at 170000 right now." - Lauren Vogel, CMAJ 